\title{
Article
}

\section{TGF $\beta$ Drives Metabolic Perturbations during Epithelial Mesenchymal Transition in Pancreatic Cancer: TGF $\beta$ Induced EMT in PDAC}

\author{
Meena U. Rajagopal ${ }^{1,+}{ }^{\oplus}$, Shivani Bansal ${ }^{1,+}{ }^{+}$, Prabhjit Kaur ${ }^{2}$, Shreyans K. Jain ${ }^{3}{ }^{\mathbb{D}}$, Tatiana Altadil ${ }^{4}$, \\ Charles P. Hinzman $\left.{ }^{5}{ }^{(}\right)$, Yaoxiang Li $^{1}{ }^{10}$, Joanna Moulton ${ }^{1}{ }^{(\mathbb{C}}$, Baldev Singh ${ }^{1}$, Sunil Bansal ${ }^{1}$, \\ Siddheshwar Kisan Chauthe ${ }^{6}$, Rajbir Singh ${ }^{2}$, Partha P. Banerjee ${ }^{5}$, Mark Mapstone ${ }^{7}$, Massimo S. Fiandaca ${ }^{7,8}$, \\ Howard J. Federoff ${ }^{7}$, Keith Unger ${ }^{9}$, Jill P. Smith ${ }^{10}$ and Amrita K. Cheema ${ }^{1,5, *}$
}

check for

updates

Citation: Rajagopal, M.U.; Bansal, S.; Kaur, P.; Jain, S.K.; Altadil, T.; Hinzman, C.P.; Li, Y.; Moulton, J.; Singh, B.; Bansal, S.; et al. TGF $\beta$ Drives Metabolic Perturbations during Epithelial Mesenchymal Transition in Pancreatic Cancer: TGF $\beta$ Induced EMT in PDAC. Cancers 2021, 13, 6204. https:// doi.org/10.3390/cancers13246204

Academic Editor:

Eva Karamitopoulou

Received: 1 October 2021

Accepted: 6 December 2021

Published: 9 December 2021

Publisher's Note: MDPI stays neutral with regard to jurisdictional claims in published maps and institutional affiliations.

Copyright: (c) 2021 by the authors. Licensee MDPI, Basel, Switzerland. This article is an open access article distributed under the terms and conditions of the Creative Commons Attribution (CC BY) license (https:/ / creativecommons.org/licenses/by/ $4.0 /)$.
1 Department of Oncology, Georgetown University Medical Center, Washington, DC 20057, USA; meena.rajagopal@nih.gov (M.U.R.); sm3451@georgetown.edu (S.B.); y1814@georgetown.edu (Y.L.); jm3330@georgetown.edu (J.M.); bs1126@georgetown.edu (B.S.); sb1886@georgetown.edu (S.B.)

2 Department of Botany, Khalsa College, Amritsar 143002, India; prabhjitkaur@khalsacollege.edu.in (P.K.); sohirajbir@gmail.com (R.S.)

3 Department of Pharmaceutical Engineering \& Technology, Indian Institute of Technology, Banaras Hindu University, Varanasi 221005, India; sjain.phe@iitbhu.ac.in

4 Biomedical Research Group in Gynaecology, Vall Hebron Research Institute (VHIR), Universitat Autònoma de Barcelona, 08035 Barcelona, Spain; altadill@ab-biotics.com

5 Department of Biochemistry and Molecular and Cellular Biology, Georgetown University Medical Center, Washington, DC 20057, USA; cph51@georgetown.edu (C.P.H.); ppb@georgetown.edu (P.P.B.)

6 Department of Natural Products, National Institute of Pharmaceutical Education and Research (NIPER), Ahmedabad 380054, India; siddheshwarchauthe@gmail.com

7 Department of Neurology, University of California, Irvine, CA 92697, USA; mark.mapstone@uci.edu (M.M.); mfiandac@uci.edu (M.S.F.); federoff@uci.edu (H.J.F.)

8 Department of Neurological Surgery, University of California, Irvine, CA 92697, USA

9 Radiation Medicine, Med-Star Georgetown University Hospital, Washington, DC 20057, USA; kru2@georgetown.edu

10 Department of Medicine, Georgetown University Medical Center, Washington, DC 20057, USA; jps261@georgetown.edu

* Correspondence: akc27@georgetown.edu; Tel.: +1-202-687-2756; Fax: +1-202-687-8860

+ Both authors contributed equally.

Simple Summary: Pancreatic cancer is an aggressive disease with most patients diagnosed at late stages resulting in poor outcomes. While it is known that pancreatic tumor cells undergo epithelial to mesenchymal transition, the metabolic alterations accompanying that transition are not characterized. This study leveraged a metabolomics approach to understand the small molecule and biochemical perturbations that can be targeted for designing strategies for improving outcomes in pancreatic cancer.

Abstract: Pancreatic ductal adenocarcinoma (PDAC) is a highly lethal malignancy wherein a majority of patients present metastatic disease at diagnosis. Although the role of epithelial to mesenchymal transition (EMT), mediated by transforming growth factor beta (TGF $\beta$ ), in imparting an aggressive phenotype to PDAC is well documented, the underlying biochemical pathway perturbations driving this behaviour have not been elucidated. We used high-resolution mass spectrometry (HRMS) based molecular phenotyping approach in order to delineate metabolic changes concomitant to TGF $\beta$ induced EMT in pancreatic cancer cells. Strikingly, we observed robust changes in amino acid and energy metabolism that may contribute to tumor invasion and metastasis. Somewhat unexpectedly, TGF $\beta$ treatment resulted in an increase in intracellular levels of retinoic acid (RA) that in turn resulted in increased levels of extracellular matrix (ECM) proteins including fibronectin (FN) and collagen (COL1). These findings were further validated in plasma samples obtained from patients with resectable pancreatic cancer. Taken together, these observations provide novel insights into small molecule dysregulation that triggers a molecular cascade resulting in increased EMT-like changes in pancreatic cancer cells, a paradigm that can be potentially targeted for better clinical outcomes. 
Keywords: tumor microenvironment; pancreatic cancer; TGF beta; 9-cis retinoic acidPANC-1 cells; epithelial mesenchymal transition

\section{Introduction}

Pancreatic ductal adenocarcinoma (PDAC) has been projected to become the second most common lethal cancer by 2030 [1]. The poor prognosis and less than $10 \%$ survival rate of PDAC is mainly attributed to late diagnosis due to the lack of sensitive and specific biomarkers that can be leveraged for early detection [2,3]. Despite the high prevalence of KRAS mutations in pancreatic cancer, therapeutic strategies targeting KRAS have thus far been ineffective. Additionally, treatments with anti-proliferative drugs such as gemcitabine in PDAC have limited effectiveness in part due to the dense fibrosis of the pancreatic tumor microenvironment (TME) and because of the ability of the tumor cells to undergo early epithelial mesenchymal transition (EMT) [4]. Multiple studies suggest that targeting the transforming growth factor- $\beta$ (TGF $\beta$ ) pathway may be a viable therapeutic approach [5]. TGF $\beta$ is a well-known inducer of EMT that is hyperactive in PDAC. EMT is reported to be essential for the dissemination of cancer cells resulting in metastasis in PDAC [6,7]. The role of TGF $\beta$ in late stage PDAC as a tumor promoter is well documented; hence, blocking this signaling pathway is an attractive target for developing more effective therapeutics [8]. However, the role of TGF $\beta$ in early PDAC remains ambiguous since there are conflicting reports that suggests its dual nature as both a tumor promoter and suppressor $[9,10]$. In addition, TGF $\beta$-mediated signaling is known to induce alterations in the tumor microenvironment resulting in desmoplasia [11]. Desmoplasia results from increased proliferation of pancreatic stellate cells (PSC) in the tumor microenvironment along with concomitant changes in other extracellular matrix (ECM) components [12,13]. The subsequent increase in tumor interstitial fluid pressure along with narrowing of the blood vessels makes the delivery of chemotherapeutic agents at the tumor site a daunting task and contributes to overall chemoresistance [14]. Taken together, EMT induced aggressiveness and desmoplasia hinder effective treatment of PDAC patients resulting in chemoresistance and disease relapse [15].

Given the pivotal role played by EMT in PDAC, our goal was to identify metabolic changes associated with EMT in pancreatic cancer that would correlate with tumor progression and metastasis. Hence, we performed global metabolomic profiling of PANC-1 cells treated with TGF $\beta$ using UPLC-ESI-QTOF-MS (Ultra performance Liquid ChromatographyElectrospray Ionization Quadrupole-Time of Flight Mass Spectrometry) to identify robust changes in multiple metabolic pathways. Specifically, TGF $\beta$ treatment resulted in an accumulation of oncometabolites including those that have been reported to promote tumor invasion in PANC-1 cells. We also found an increase in intracellular levels of retinoic acid that seemed to cause an increase in the expression levels of major components of ECM proteins such as fibronectin (FN) and collagen (COL) as well as upregulation of enzymes involved in protein glycosylation. Taken together, these results, for the first time, suggest that TGF $\beta$-induced EMT is accompanied by metabolic changes and small molecule effectors that impact the tumor microenvironment in a manner that is conducive to tumor growth and invasiveness in pancreatic cancer.

\section{Materials and Methods}

Reagents and chemicals for mass spectrometry: All LC-MS grade solvents including chloroform, ACN, water and methanol were purchased from Fisher Optima grade, Fisher Scientific (Hampton, NJ, USA). High purity formic acid (99\%) was purchased from ThermoScientific (Rockford, IL, USA). Ammonium formate, debrisoquine and 4-nitrobenzoic acid (4-NBA) were purchased from Sigma-Aldrich (St. Louis, MO, USA). TGF $\beta$, 9-cis retinoic acid and all trans-retinoic acid were purchased from R\&D systems. Internal standards for all trans retinoic acid (D5) and adenosine (D2) were purchased from Cambridge Isotope 
Laboratories and standards. Acetyl CoA was purchased from Cayman Chemical Company (Ann Arbor, MI, USA).

\subsection{Cell Lines and Culture Conditions}

All pancreatic cancer cell lines used in the study were obtained from the Tissue Culture Shared Resource in Lombardi Comprehensive Cancer Center. PANC-1 cells were cultured in Dulbecco's Modified Eagle Medium (DMEM) supplemented with 10\% FBS, $1 \%$ L-glutamine, $1 \%$ sodium pyruvate, $1 \%$ non-essential amino acids, $0.5 \%$ fungizone and $1 \%$ penicillin-streptomycin [16]. Panc02.13 cells were cultured in Roswell Park Memorial Institute (RPMI-1640) media containing 10\% FBS, 1\% L-glutamine, 1\% sodium pyruvate, $1 \%$ non-essential amino acids, $0.5 \%$ fungizone, $1 \%$ penicillin-streptomycin, $0.2 \%$ insulin and gentamycin. ASPC1 and SW1990 cells were cultured in phenol red-free Improved Minimum Essential Medium (IMEM; Invitrogen) containing 10\% fetal bovine serum (Atlanta Biologicals), $2 \mathrm{mM}$ L-glutamine, $100 \mathrm{U} / \mathrm{mL}$ penicillin $\mathrm{G}$ sodium and $100 \mu \mathrm{g} / \mathrm{mL}$ streptomycin sulfate (Sigma). All cell lines used were tested and authenticated at the Tissue Culture Shared Resource (TCSR) in Lombardi Comprehensive Cancer Center by DNA fingerprinting short tandem repeat analysis (STR). All cells were tested negative for mycoplasma and other contaminants.

Cells were grown in a humidified incubator at $37{ }^{\circ} \mathrm{C}$ at $5 \% \mathrm{CO}_{2}$ until they were about $80 \%$ confluent after which the media was removed, and cells were washed with PBS. Fresh media devoid of FBS was added, and the cells were serum starved for $24 \mathrm{~h}$. Subsequently, these were separately treated with TGF $\beta(10 \mathrm{ng} / \mathrm{mL})$ and 9-cis retinoic acid $(0.5 \mu \mathrm{M}$ and $1 \mu \mathrm{M})$ containing fresh serum-free media. All treatments were carried out for $48 \mathrm{~h}$ after which cells were harvested by scraping in PBS solution. The cell suspension was centrifuged at $1500 \mathrm{rpm}$ for $20 \mathrm{~min}$ at $4{ }^{\circ} \mathrm{C}$, supernatant was discarded and cell pellet was stored at $-80^{\circ} \mathrm{C}$ until further analysis.

\subsection{UPLC-ESI-QTOF MS Analysis}

For metabolite extraction, the cell pellets were resuspended in $100 \mu \mathrm{L}$ of water. The tubes were placed on dry ice for $30 \mathrm{sec}$ followed by $90 \mathrm{sec}$ incubation in a $37^{\circ} \mathrm{C}$ water bath and the freeze-thaw cycle was repeated three times. The samples were sonicated for $30 \mathrm{sec}$. An amount of $600 \mu \mathrm{L}$ of $50 \%$ chilled methanol containing internal standards (10 $\mu \mathrm{L}$ of debrisoquine $(1 \mathrm{mg} / \mathrm{mL}$ in water) and $50 \mu \mathrm{L}$ of $4-\mathrm{NBA}(1 \mathrm{mg} / \mathrm{mL}$ in methanol) per $10 \mathrm{~mL})$ was added to the cell pellets. The supernatant was transferred to a fresh tube, and $350 \mu \mathrm{L}$ chilled $100 \% \mathrm{ACN}$ was added. In addition, $2 \mu \mathrm{L}$ of the supernatant was set aside for protein quantification by using the Bradford method [17]. The tubes containing supernatant and ACN were vortexed, incubated on ice for $15 \mathrm{~min}$ and centrifuged at $13,000 \mathrm{rpm}$ at $4{ }^{\circ} \mathrm{C}$ for $15 \mathrm{~min}$. The supernatant was transferred to a fresh tube and dried under vacuum. The samples were resuspended in $200 \mu \mathrm{L}$ of solvent $\mathrm{A}(98 \%$ water and $2 \% \mathrm{ACN})$ and transferred to MS vial for UPLC-ESI-Q-TOF-MS analysis. An amount of $20 \mu \mathrm{L}$ from each sample was mixed to generate a pooled QC sample. The sample queue was randomized to avoid bias. Two microliters of each sample was injected onto a reverse-phase $2.1 \times 50 \mathrm{~mm}$ Acquity $1.7 \mu \mathrm{m}$ C18 column (Waters Corporation, Milford, MA, USA) using an Acquity UPLC system with a gradient mobile phase consisting of $2 \%$ acetonitrile in water containing $0.1 \%$ formic acid (solution $\mathrm{A}$ ) and $2 \%$ water in acetonitrile containing $0.1 \%$ formic acid (solution B). Each sample was resolved for $10 \mathrm{~min}$ at a flow rate of $0.5 \mathrm{~mL} / \mathrm{min}$. The gradient consisted of $100 \%$ A for $0.5 \mathrm{~min}$, then a ramp of curve 6 to $60 \% \mathrm{~B}$ from $0.5 \mathrm{~min}$ to $4.0 \mathrm{~min}$, then a ramp of curve 6 to $100 \% \mathrm{~B}$ from $4.0-8.0 \mathrm{~min}$, held at $100 \% \mathrm{~B}$ until $9.0 \mathrm{~min}$ and then a ramp of curve 6 to $100 \%$ A from $9.0 \mathrm{~min}$ to $9.2 \mathrm{~min}$, followed by a hold at $100 \%$ A until $10 \mathrm{~min}$. The column eluent was introduced directly into the mass spectrometer by electrospray. Mass spectrometry was performed on a Q-TOF instrument (QTOF Premiere, Waters, Columbia, MD, USA) operating in either negative (ESI-) or positive (ESI+) electrospray ionization mode with a capillary voltage of $3200 \mathrm{~V}$ and a sampling cone voltage of $20 \mathrm{~V}$ in negative mode and $35 \mathrm{~V}$ in positive mode. The desolvation gas flow was set to $800 \mathrm{~L} / \mathrm{h}$, and the 
temperature was set to $350{ }^{\circ} \mathrm{C}$. The cone gas flow was $25 \mathrm{~L} / \mathrm{h}$, and the source temperature was $120^{\circ} \mathrm{C}$. Data were acquired in centroid mode from 50 to $850 \mathrm{~m} / \mathrm{z}$ in MS scanning. Accurate mass was maintained by infusion of LockSpray interface with Leucine Enkaphalin $\left(556.2771[\mathrm{M}+\mathrm{H}]^{+}\right.$and $\left.554.2615[\mathrm{M}-\mathrm{H}]^{-}\right)$. Pooled quality control (QC) samples for each matrix comprised an aliquot of all samples in the study set, thus representing a universal set of metabolites. Initially the column was conditioned using this QC sample, and thereafter it was injected after every ten injections to account for reproducibility of the LC-MS data. In addition, a blank and a MetMix standard were randomly injected at an average interval of 10 samples to monitor mass accuracy, retention time drifts and sample carryover. LC-MS data were pre-processed using the XCMS software [18]. We performed multivariate data analysis using R package [19]. Statistically significant $m / z$ and FDR adjusted $p$-value $\leq 0.05$ were run on the UPLC-QToF instrument in the MS/MS mode. Identities for a subset of metabolites were validated by MS/MS. Human Metabolome Database (www.hmdb.ca (accessed on 18 November 2018)), Madison Metabolomics Consortium Database (mmcd.nmrfam.wisc.edu (accessed on 18 November 2018)), LIPID MAPS (www. lipidmaps.org (accessed on 18 November 2018)), KEGG (www.kegg.jp/kegg (accessed on 18 November 2018)) and Metlin (metlin.scripps.edu (accessed on 18 November 2018)) were used for accurate mass-based putative identification of metabolites. Tandem mass spectrometry was used to putatively identify annotations using fragmentation matching.

\subsection{Targeted Metabolomics Using 7500 QTRAP}

Targeted metabolomics method, developed in-house, was used to quantitate $>500$ endogenous metabolites using QTRAP ${ }^{\circledR} 7500$ LC-MS/MS System (Sciex, MA, USA). For this purpose, $50 \mu \mathrm{L}$ of PBS was added to the cell pellet, and the sample tube was plunged into dry ice for $30 \mathrm{sec}$ and $37^{\circ} \mathrm{C}$ water bath for $90 \mathrm{sec}$. This cycle was repeated for two more times and then samples were sonicated for $1 \mathrm{~min}$, and $100 \mu \mathrm{L}$ of chilled isopropanol containing internal standards (debrisoquine and 4-nitrobenzoic acid for positive and negative mode of targeted metabolomics, respectively, and labelled lipid standards for each class for targeted lipidomics) was added. The samples were vortexed for $1 \mathrm{~min}$ and kept on ice for $30 \mathrm{~min}$ followed by incubation at $-20{ }^{\circ} \mathrm{C}$ for $2 \mathrm{~h}$ for protein precipitation. The samples were centrifuged at $13,000 \mathrm{rpm}$ for $20 \mathrm{~min}$ at $4{ }^{\circ} \mathrm{C}$. The supernatant was transferred to MS vial for LC-MS analysis. An amount of $20 \mu \mathrm{L}$ of each prepared sample was mixed to generate the pooled QC sample. An amount of $5 \mu \mathrm{L}$ of the prepared sample was injected onto a Kinetex $2.6 \mu \mathrm{m}$ polar C18 $100 \AA 100 \times 3.0 \mathrm{~mm}$ (Phenomenex, CA, USA) using SIL-30 AC auto sampler (Shimazdu, Kytoto, Japan) connected with a high flow LC-30AD solvent delivery unit (Shimazdu, Kytoto, Japan) and CBM-20A communication bus module (Shimazdu, Kytoto, Japan) online with QTRAP 7500 (Sciex, MA, USA) operating in positive and negative ion modes. A binary solvent comprising water with $0.1 \%$ formic acid (solvent A) and acetonitrile with $0.1 \%$ formic acid (solvent $\mathrm{B}$ ) was used. The extracted metabolites were resolved at $0.2 \mathrm{~mL} / \mathrm{min}$ flow rate. The LC gradient conditions were as follows: Initial- $100 \%$ A, $0 \%$ B for $2.1 \mathrm{~min} ; 14 \mathrm{~min}$ for $5 \% \mathrm{~A}$ and $95 \% \mathrm{~B}$ until $15 \mathrm{~min}$; and $15.1 \mathrm{~min}$ for $100 \% \mathrm{~A}$ and $0 \% \mathrm{~B}$ until $20 \mathrm{~min}$. The auto sampler and oven were kept at $15^{\circ} \mathrm{C}$ and $30^{\circ} \mathrm{C}$, respectively. Source and gas settings for the method were as follows: curtain gas $=40 ; \mathrm{CAD}$ gas $=9$; ion spray voltage $=1700 \mathrm{~V}$ in positive mode and ion spray voltage $=1600 \mathrm{~V}$ in negative mode; temperature $=350{ }^{\circ} \mathrm{C}$; ion source gas $1=30$; and ion source gas $2=50$.

\subsection{Targeted Lipidomics Using 7500 QTRAP}

A targeted lipidomics method, developed in-house, was used to quantitate 22 classes of lipid metabolites such as diacylglycerols (DAGs), cholesterol esters (CEs), sphingomyelins (SMs), phosphtatidylchloine (PCs), triacylglycerols (TAGs), free fatty acids (FFAs), ceramides (CERs), dihydroceramides (DCERs), hexosylceramides (HCERs), lactosylceramides (LCERs), phosphatidylethnolamines (PEs), lysophosphtatidylchloines (LPCs), lysophosphatidylethnolamines (LPEs), phosphatidylinositols (PIs), lysophosphatidylinositols (LPIs), phosphatidylserines (PSs), phosphatidic acid (PAs), lysophosphatidic acid (LPAs), monoa- 
cyl glycerols (MAGs), acylcarnitines (ACs), phosphatidyl glycerols (PGs) and lysophosphatidyl glycerols (LPGs) using QTRAP ${ }^{\circledR} 7500$ LC-MS/MS System (Sciex, MA, USA). For this purpose, the cell samples prepared above for the targeted metabolomics were used. A binary solvent comprising acetonitrile/water $95 / 5$ with $10 \mathrm{mM}$ ammonium acetate as solvent $\mathrm{A}$ and acetonitrile/water $50 / 50$ with $10 \mathrm{mM}$ ammonium acetate as solvent $\mathrm{B}$ was used for the resolution. Lipids were resolved on Xbridge amide $3.5 \mu \mathrm{m}, 4.6 \times 100 \mathrm{~mm}$ (Waters) at $0.7 \mathrm{~mL} / \mathrm{min}$ flow rate. The LC gradient conditions were as follows: Initial- $100 \%$ A at $0.2 \mathrm{~mL} / \mathrm{min}, 0 \% \mathrm{~B} ; 2.0 \mathrm{~min}$ at $90.9 \% \mathrm{~A}$ and $9.1 \% \mathrm{~B}$ at $0.2 \mathrm{~mL} / \mathrm{min} ; 11.0 \mathrm{~min}$ at $50 \% \mathrm{~A}$ and $50 \% \mathrm{~B}$ at $0.7 \mathrm{~mL} / \mathrm{min} ; 11.5 \mathrm{~min}$ at $30 \% \mathrm{~A}$ and $70 \% \mathrm{~B}$ at $0.7 \mathrm{~mL} / \mathrm{min}$; and $12.50 \mathrm{~min}$ at $0 \% \mathrm{~A}, 100 \% \mathrm{~B}$ at $0.7 \mathrm{~mL} / \mathrm{min}, 15.00 \mathrm{~min}$ at $0 \% \mathrm{~A}, 100 \% \mathrm{~B}$ at $0.7 \mathrm{~mL} / \mathrm{min}$ and $15.10 \mathrm{~min}$ at $100 \% \mathrm{~A}$ and $0 \% \mathrm{~B}$ at $0.2 \mathrm{~mL} / \mathrm{min}$ until $17.00 \mathrm{~min}$. The auto sampler and oven were kept at $15{ }^{\circ} \mathrm{C}$ and $35^{\circ} \mathrm{C}$, respectively. Source and gas setting were as follows: curtain gas $=45$; CAD gas $=9$; ion spray voltage $=5200 \mathrm{~V}$ in positive mode and ion spray voltage $=4500 \mathrm{~V}$ in negative mode; temperature $=350{ }^{\circ} \mathrm{C}$; ion source gas $1=45$; and ion source gas $2=50$.

\subsection{Quality Control and Measures to Monitor Data Quality}

The reproducibility and high quality of the LC-MS data were ensured by using several measures. The column was conditioned using pooled QC samples initially, and pooled QC samples were also injected periodically (after every four sample injections) to monitor shifts in signal intensities and retention time as measures of reproducibility and data quality of the LC-MS data. Pooled QC samples were routinely applied to assess and correct for any analytical variance. We also have blank solvent runs between a set of samples (after every 4 samples on either side pooled QC samples) to monitor sample-to-sample carry-over effects. In order to monitor instrumental variance, we also ran an NIST plasma sample (after every 4 samples) prepared in the same manner as actual samples.

\subsection{Data Processing and Statistical Analysis for QTRAP 7500 Metabolomics and Lipidomics Data}

Abundance measurement for metabolites was expressed as intensity units (area under the curve) that were initially normalized to internal standards and processed using Sciex OS 2.0.1 (Sciex). The data were pre-processed using a signal/noise ratio $>20: 1$ and retention time (RT) tolerance of $5 \mathrm{~s}$ after manually checking of metabolites peak to find the reliable features. We also use $20 \%$ of missing values in each feature as filter out criteria. Missing values were imputed by half of the minimum positive value in the original data. Thereafter, we used $20 \%$ of the coefficient of variation (CV) as our filter criteria to remove any possible noises before data normalization. Analytical drifts (if any) were corrected by quality control based robust LOESS signal correction (QC-RLSC) [20]. All analyses were performed using R package ( $\mathrm{v}$ 4.0.3). The normalized LC-MS data were log transformed and Pareto scaled. For the 12 samples in the study set, the level of differential expression for each metabolite was calculated using an unpaired t-test, comparing control vs. TGF $\beta$ treated, and constrained by FDR corrected $p$-value $<0.05$. Figures were created using $\mathrm{R}$ and BioRender (www.BioRender.com) accessed on 21 June 2021.

\subsection{Reverse Transcription-Polymerized Chain Reaction (RT-PCR)}

Reverse-Transcription Reaction was performed following the standard protocol of RT $^{2}$ First Strand Kit (Qiagen) and was analyzed by real time PCR. qRT-PCR on EMT related genes, genes involved in glycosylation and genes involved in glucose transport and metabolism were performed according to manufacturer's protocol, and they are described in detail in Supplementary Materials. The data were analyzed based on $\Delta \Delta \mathrm{Ct}$ method as per the instructions of the manufacturer. 
2.8. Ultra-Performance Liquid Chromatography-Multiple Reaction Monitoring-Mass Spectrometry (UPLC-MRM-MS) Based Targeted Metabolomics

2.8.1. MRM-MS Quantitation of Intra-Cellular Levels of Retinoic Acid and Amino Acids in PANC-1 Cells

PANC-1 cells were grown in DMEM, were treated with $10 \mathrm{ng} / \mathrm{mL}$ of TGF $\beta$ or DMSO for $48 \mathrm{~h}$ and harvested as described earlier. Retinoic acid was extracted using a slightly modified protocol as previously described by Kane et al. [21]. Amino acids were extracted using the commercially available protocol for Absolute IDQ p180 kit (Biocrates Innsbruck) that involves steps for protein removal, internal standard normalization and derivatization using phenylisothiocyanate. Measurements were made in biological triplicates for each treatment; six calibration standards and three quality control samples were integrated in the analyses. All samples were resolved on a UPLC system online with a triple quadrupole MS (Xevo TQ-S, Waters Corporation) operating in the MRM mode. Quantitation was performed by comparing response values of treated samples to controls (normalized to stably labelled isotope standard for a given metabolite).

\subsubsection{MRM-MS Based Quantitation of Metabolites (Acetyl CoA) in Human} Plasma Samples

Four groups of samples were used for quantitative analysis of metabolites including 11 normal controls $(n=11)$; stages IA, IB and IIA PDAC $(n=12)$; Intraductal Pancreatic Mucinous Neoplasm (IPMN) $(n=10)$; and pancreatitis $(n=11)$. All plasma samples were prepared using a standard protocol. Detailed protocol of metabolite extraction, LC method employed here is explained in detail in Supplementary Materials, and related figures (Figure S1) are included in Supplementary Data File.

\subsection{Enzyme Linked Immuno Sorbent Assay (ELISA) of Fibronectin (FN1) and O-Linked $N$-Acetylglucosamine Transferase (OGT) in Human Plasma Samples}

FN1 and OGT levels in plasma were determined using commercially available kits from Affymetrix eBioscience and human OGT ELISA kit from MyBiosource.com according to the manufacturer's recommendations. For this assay, a total of 39 plasma samples including early stage PDAC $(n=11), \operatorname{IPMN}(n=9)$ and acute pancreatitis $(n=10)$ as well as normal controls $(n=9)$ were analyzed. The clinical samples were made available through the Indivumed repository at the MedStar-Georgetown University hospital protocols while the normal controls $(n=11)$ were recruited as a part of the Rochester aging study (RAS) under approved IRB protocols [22]. Clinical and demographic characteristics of the cohort such as age, sex and ethnicity were recorded. All samples were collected under $12 \mathrm{~h}$ fasting conditions using stringent procedures for collection and storage, thus minimizing confounding by pre-analytical variables on downstream MS analyses. Other factors and coexisting conditions such as BMI, jaundice, diabetes, smoking and alcohol traits for each subject were also annotated. ELISA results are presented as the mean \pm SEM, with the number of experiments indicated in the figure's legend. Statistical significance was assessed using ANOVA for multiple comparisons with GraphPad Prism (GraphPad Software Inc., San Diego, CA, USA).

\section{Results}

\subsection{TGF $\beta$ Induced EMT in PANC-1 Cells Is Accompanied by Robust Changes in Metabolic Profiles}

We confirmed that TFG $\beta$ induced an increase in expression of $\mathrm{N}$-cadherin (CDH2) and a decrease in expression levels of E-cadherin (CDH1) at both protein and mRNA levels in accordance with previous reports as hallmarks of EMT induction in PANC-1 cells that carry a mutant KRAS allele [23] (Figure S2A-D). In contrast, there was no significant change in cellular morphology or $\mathrm{N}$-cadherin levels in TGF $\beta$-treated Panc02.13 cells, a KRAS wt pancreatic adenocarcinoma cell line, although a slight decrease in the levels of E-cadherin was observed (Figure S2E-H). Moreover, there was no change in the intracellular levels of retinoic acid upon TGF $\beta$ treatment in Panc02.13 cells (Figure S2I). 
These results suggest that mutant KRAS may be required for TGF $\beta$ mediated induction of EMT in pancreatic cells. Another difference between PANC-1 and Panc02.13 cells is that the former expresses high levels of the cholecystokinin-B receptor (CCK-BR) that is responsible to tumor growth when activated [24] and the Panc02.13 cells lack CCK-BR and only have CCK-AR [25]. We have shown that blockade of the CCK-BR signaling pathway in mice bearing PANC-1 orthotopic tumors with proglumide decreases metastases by inhibiting EMT [26]. The major ligand that activates CCK-BR is gastrin; and TGFB has been shown to activate the gastrin promoter [27].

In order to delineate metabolic changes concomitant to EMT, we performed untargeted profiling of PANC-1 cells treated with TGF $\beta$. Pre-processing of MS data yielded 2000 and 1500 features in the electrospray (ESI) positive and negative ionization modes, respectively. Inherent differences in metabolic profiles (with and without TGF $\beta$ treatment) were visualized using a descriptive principal component analysis (PCA) plot that showed maximal separation between the two comparative groups (Figure 1A). Next, with a fold-change criterion of $\geq 0.5$ or $\leq 2.0$ and $p$-value $\leq 0.05$ ), multiple metabolites were found to be significantly dysregulated upon TGF $\beta$ treatment which were visualized as volcano plots (Figure 1B and Table S1). Subsequently, we putatively annotated a subset of metabolites that were significantly dysregulated upon TGF $\beta$ treatment using tandem mass spectrometry (MS/MS), which is listed in Table S2. Figure S2J, shows MS/MS validations of a subset of metabolites that were found to be significantly dysregulated in PANC-1 cells upon TGF $\beta$ treatment. We found retinoic acid, pseudouridine and prostaglandin E2 to be significantly upregulated in TGF $\beta$-treated PANC-1 cells. Interestingly, reduced glutathione levels were significantly downregulated, suggesting an increase in the oxidative stress status of TGF $\beta$-treated PANC- 1 cells, which is a finding that has been reported by other groups [28]. We also observed upregulation of several amino acids in TGF $\beta$ treated PANC-1 cells, which was further confirmed via multiple reaction monitoring based mass spectrometry (MRM-MS) (Figure 1C, Table S3).

Next, we performed targeted quantification to confirm other significant metabolic dysregulations in PANC-1 cells upon TGF $\beta$ treatment, as observed initially with untargeted profiling. Hence, we quantified a large number of metabolites and lipids in PANC-1 cells treated with TGF $\beta$ or DMSO using in-house developed targeted metabolomics (includes >500 small polar molecules) and deep lipidomics (22 classes of lipids) MRM-MS-based panels on a triple quadrupole mass spectrometer (QTRAP ${ }^{\circledR} 7500$ LC-MS/MS system, Sciex, MA, USA). Data pre-processing was followed by statistical and multivariate analyses that enabled the visualization of distinctive metabolic profiles of PANC-1 treated with TGF $\beta$ as compared to control (Table S4). We used hierarchical clustering to examine differential abundance and found robust changes, including significant upregulation of amino acids and their derivatives and TCA metabolites after TGF $\beta$ treatment (Figure 2A). Another striking observation was elevation in branched chain amino acids (BCAAs), leucine, isoleucine and valine in accordance with a previously reported study [29].

We also observed significant upregulation of TCA cycle metabolites such as 2-hydroxyglutaric acid, oxoglutarate, isocitrate, malate and fumarate. In addition, the intracellular levels of oxalate, maleic acid, ascorbate and NADP were also found to be upregulated. Most of the metabolic dysregulations observed herein represent interconnected metabolic networks that span central roles in several pathways such as glutaminolysis, the TCA cycle and glycolysis along with amino acid metabolism (Figure 2B).

Dyslipidaemia after TGF $\beta$ treatment mainly involved downregulations in the levels of lipid species such as FFAs, LPEs, PSs and TAGs. The downregulated FFAs included myristoleic acid, oleic acid, linoleic acid, dihomo-linoleic acid, arachidonic acid and docosatetraenoic acid (Table S4). 


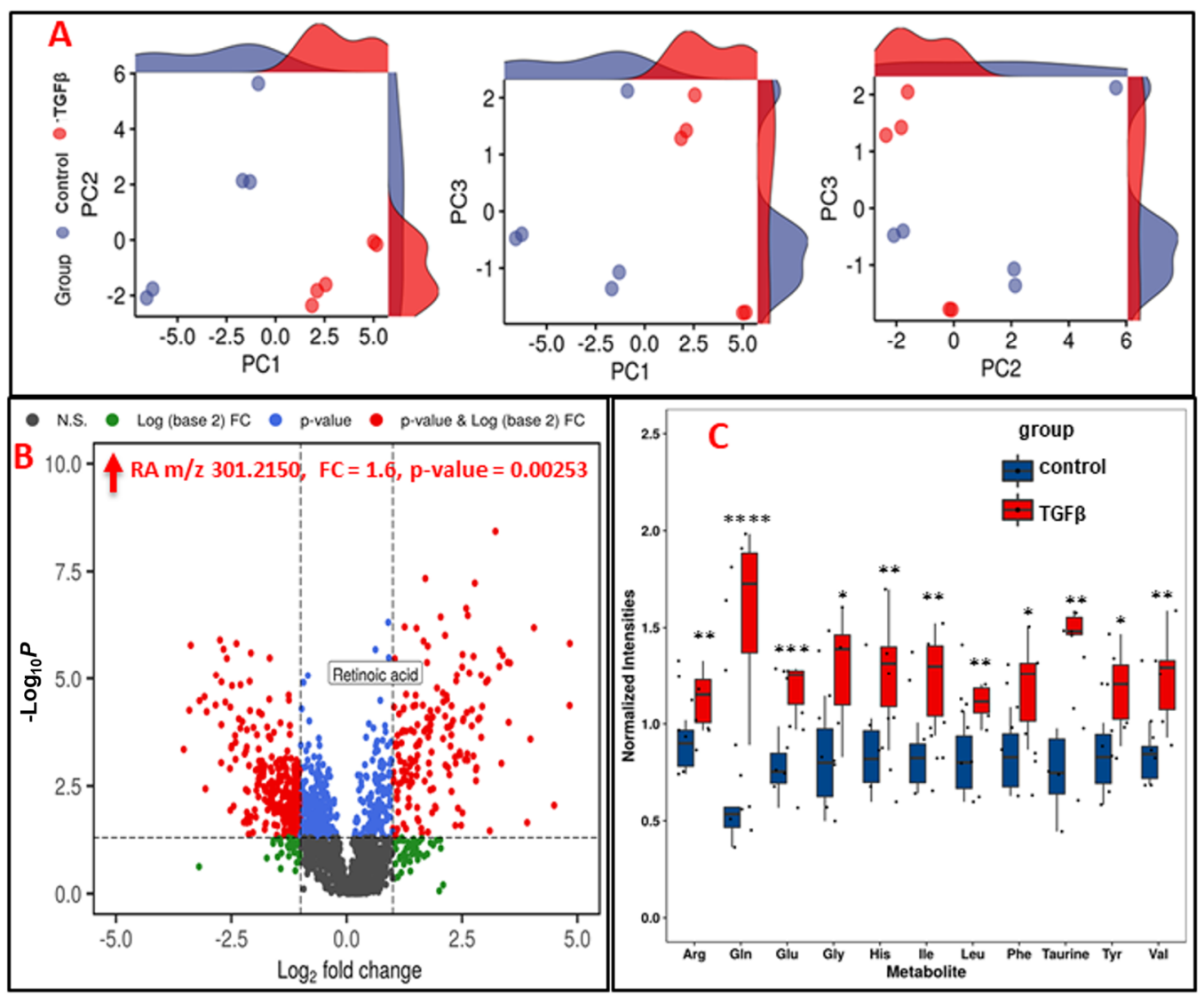

Figure 1. TGF $\beta$ treatment of PANC-1 cells induces robust changes in metabolism. (A). PCA plot showing the separation between TGF $\beta$ and DMSO treated PANC-1 cells based on metabolomics profiles. The $X$-axis shows interclass separation while $Y$-axis illustrates the intra-class variance. (B). Volcano plot showing combined visualization of dysregulated metabolites based on fold change on $X$-axis and $p$-value on $Y$-axis. Each dot represents a feature; red colored dots have significant FC $(\geq 0.5$ or $\leq 2.0)$ and $p$-value $(\leq 0.05)$. (C) Targeted MRM-MS-based quantitative analysis of amino acids that were found to be significantly (FDR $\leq 0.05)$ dysregulated in PANC-1 cells upon TGF $\beta$ treatment. Box and whisker plots representing indicated metabolite levels in PANC-1 cells after TGF $\beta$ treatment. ${ }^{*} p$-value $<0.05 ;{ }^{* *} p$-value $<0.005 ;{ }^{* * *} p$-value $<0.0005$; $* * * *$-value $<0.00005$.

An interesting and somewhat unexpected observation was a significant increase in the intracellular levels of retinoic acid following TGF $\beta$ treatment of PANC-1 cells. We confirmed this finding by using other established pancreatic cancer cell line models by targeted mass spectroscopy (Figure 3A). Given the pivotal role of retinoic acid as a cellular differentiating agent, we sought to understand the role of this small molecule in TGF $\beta$ induced EMT in PANC-1 cells. We used 9-cis RA and all trans-retinoic acid (atRA) to determine if downstream signaling events, at least in part following TGF $\beta$ treatment, were mediated by a particular isomer of RA. Hence, we treated PANC-1 cells with $0.5 \mu \mathrm{M}$ 9-cis RA and $1 \mu \mathrm{M}$ (at) RA [30]. As shown in Figure 3B,C, treatment of PANC-1 cells with $0.5 \mu \mathrm{M}$ 9-cis RA caused a significant decrease in E-cadherin although there was no increase in $\mathrm{N}$-cadherin. Immunofluorescent microscopy showed significant changes in morphology in 9-cis RA treated PANC-1 cells (Figure 3D). Previously, Byers et al. have reported morphological changes in breast cancer cells upon treatment with 9-cis RA [31]. On the other hand, (at) RA treated PANC-1 cells showed no significant changes either in cellular morphology or the relative expression of $\mathrm{CDH} 1$ and $\mathrm{CDH} 2$ (Figure $\mathrm{S} 2 \mathrm{~K}-\mathrm{M}$ ), suggesting that 9-cis RA was more likely to act as an effector molecule following TGF $\beta$ treatment. 


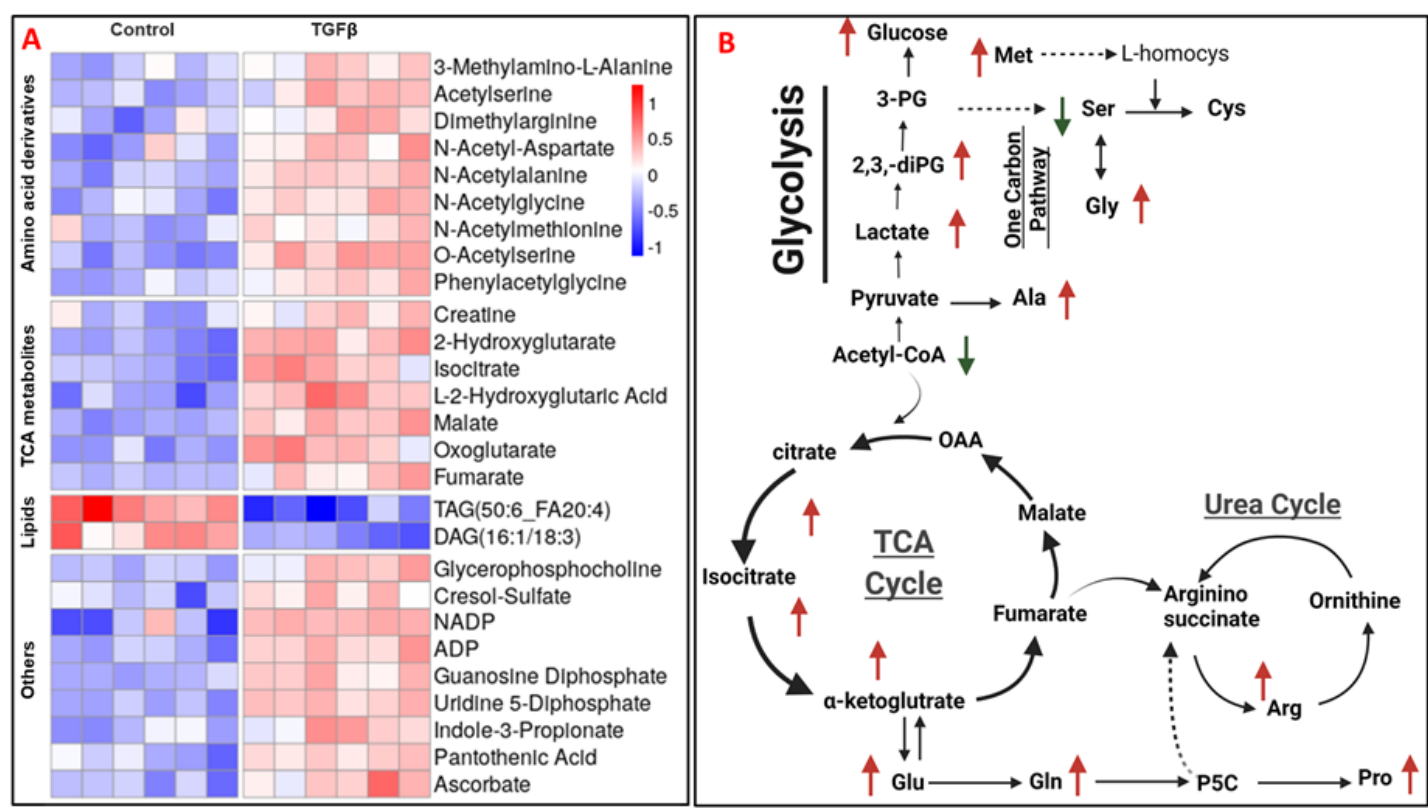

Figure 2. (A). Heat map visualization of significantly dysregulated metabolites having FDR $\leq 0.05$, corresponding to their relative intensity levels in PANC-1 control and PANC-1 TGF $\beta$ treated groups. (B). Pathway perturbations in energy and amino acid metabolism in PANC-1 cells following TGF $\beta$ treatment.

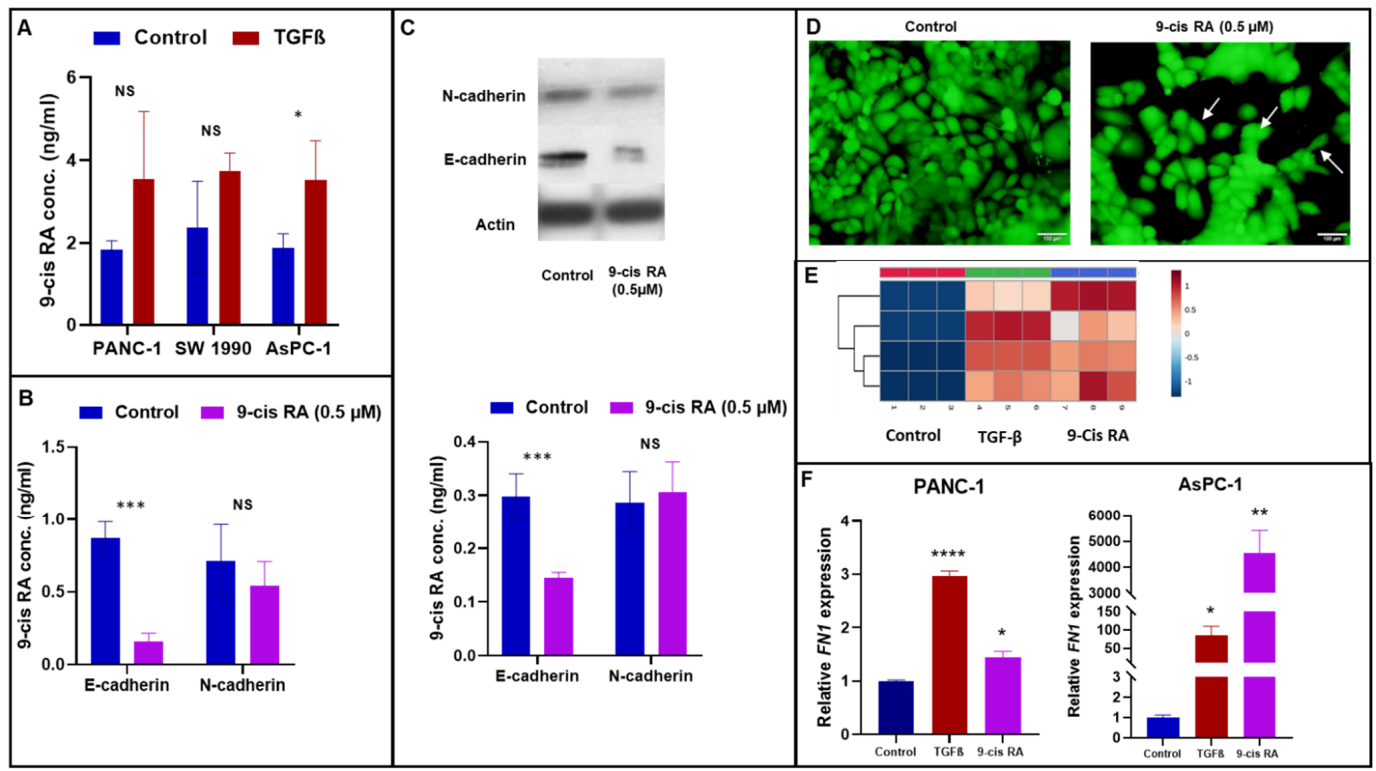

Figure 3. 9-cis RA causes a decrease in E-cadherin expression in PANC 1 cells. (A). TGF $\beta$ treatment in PANC1, SW1990 and ASPC1 cell lines resulted in an increase in intracellular levels of 9-cis Retinoic acid than compared to control treated cells. 9-cis RA was measured using targeted mass spectrometry. (B). Gene expression of E-cadherin and N-cadherin in PANC1 cells following 9-cis RA treatment. The bars indicate relative expression of the indicated genes (mean $\pm \mathrm{SD}$ from three determinations) adjusted with GAPDH. (C). Western blot analysis showing relative levels of E-cadherin and N-cadherin after 9-cisRA treatment of PANC1 cells. (D). Phase Contrast Microscopy shows altered morphology in 9-cis RA treated PANC1 cells. PANC1 cells were serum starved for $24 \mathrm{~h}$ and subsequently treated with $0.5 \mu \mathrm{M} 9$-cis RA for $48 \mathrm{~h}$ while the controls were treated with DMSO under the same conditions. After 9-cis-RA treatment, PANC1 cells organize to form elongated epithelial structures, similarly to EMT (shown by arrows). (E). Heat map of a subset of dysregulated genes in PANC1 analyzed by EMT array in response to treatment with TGF $\beta$ and 9-cis RA. Each row on the heat map represents normalized expression for a unique gene. (F). Bar graph showing increase in transcript levels of FN1 in PANC-1 and AsPC-1 cells as determined by RTPCR, in response to TGF $\beta$ and 9-cis RA treatments, relative to control. FN1 expression within each group was normalized to levels of GAPDH. ${ }^{*} p$-value $<0.05 ;{ }^{* *} p$-value $<0.005 ;{ }^{* * *} p$-value $<0.0005 ;{ }^{* * *} p$-value $<0.00005$. 
Next, we estimated the intracellular levels of 9-cis RA in PANC-1 cells upon TGF $\beta$ treatment using targeted MRM-MS (MRM transitions detailed in Table S5). The intracellular concentration of retinoic acid after TGF $\beta$ treatment was found to be approximately $0.5 \mu \mathrm{M}$, which was calculated by extrapolating from a standard calibration curve (Figure S3). All our subsequent treatments were designed to study the role of this small molecule in modulating EMT-mediated metabolic reprogramming; therefore, we used $0.5 \mu \mathrm{M}$ of 9-cis RA for treating PANC-1 cells to mimic intracellular concentrations.

3.2. TGF $\beta$ and 9-cis RA Treatment Markedly Dysregulates Genes Involved in ECM Remodeling in PANC-1 Cells

One of the intriguing observations in the study thus far was that treatment with 9-cis RA caused a partial EMT response (loss of epithelial morphology and downregulation of E-cadherin); however, we did not observe an increase in mesenchymal markers such as $\mathrm{N}$-cadherin or vimentin. We took a multifaceted approach to identify the precise role of 9-cis RA in TGF $\beta$-mediated EMT induction. First, we examined the effect of TGF $\beta$ and 9-cis RA treatments on the expression of a panel of 84 known markers of EMT in PANC- 1 cells using a human EMT cDNA array. As expected, treatment with $10 \mathrm{ng} / \mathrm{mL}$ of TGF $\beta$ elicited a classical and complete EMT response with alterations in the expression levels of genes known to be involved in cell growth and proliferation such as AKT1 (AKT serine/threonine kinase 1), BMP7 (bone morphogenetic protein 7), EGFR (epidermal growth factor receptor), $I L K$ (integrin linked kinase), MST1R (macrophage stimulating 1 receptor) and TGF $\beta 3$ (transforming growth factor beta 3), and SNAI3 (snail family transcriptional repressor 3), SPARC (secreted protein acidic and cysteine rich), KRT14 (keratin 14), KRT19 (keratin 19) and TSPAN13 (tetraspanin 13) significantly decreased compared to control. The expression of PDGFRB (platelet-derived growth factor receptor beta) that is involved in cell mobility and migration along with ITGAV (integrin subunit alpha V) significantly increased after TGF $\beta$ treatment. Transcription factors GSC (goosecoid homeobox) and STAT3 (signal transducer and activator of transcription 3) were at least 1.5 -fold reduced in TGF $\beta$-treated cells compared to control (Table S6). Moreover, the platelet derived growth factor receptor $\beta$ (PDGFRB) gene that is known to drive EMT mediated metastasis in PDAC [32] was about 8 -fold up after treatment with TGF $\beta$. As reported previously, treatment with TGF $\beta$ caused upregulation of genes involved in the protein components of the ECM, namely COL3A (collagen type 3A, Figure S4) and FN1 (fibronectin, Figure 3E,F). The observed relative expression of the aforementioned genes after TGF $\beta$ treatments compared to control is indicative of the complex mechanisms by which TGF $\beta$ induces EMT.

On the other hand, while treatment with 9-cis RA significantly increased the expression of ECM component markers such as fibronectin, collagen family and PDGFRB compared to controls (no treatment), it did not trigger a complete EMT induction response. Metalloproteinases (MMP2 and MMP9), known to be involved in the degradation of ECM proteins [33], were significantly downregulated upon 9-cis RA treatment compared to TGF $\beta$ treatment but were not significantly different from that of controls. We also observed a marked downregulation in the expression of $B M P 7$, a known negative regulator of TGF $\beta$ induced EMT [34]. We performed a wound healing assay and measured cell migration both 24 and $48 \mathrm{~h}$ post treatment with either 9-cis RA or TGF $\beta$. In both PANC- 1 and AsPC-1 cells, we found a significant increase in the migratory potential of cells at both time points after treatment with either TGF $\beta$ or 9-cis RA (Figure S5). Overall, treatment with 9-cis RA induced significant change in PANC-1 and AsPC-1 cells even without inducing significant changes in all known markers of EMT. These results suggest that 9-cis RA and TGF $\beta$ treatments of pancreatic cancer cells have functional consequences. However, the changes induced by 9-cis RA and TGF $\beta$ do have functional consequences [35].

\subsection{TGF $\beta$ and 9-cis RA Promote EMT Induced O-Glycosylation}

Our studies thus far demonstrated changes in expression patterns of protein components of ECM predominantly FN1 upon 9-cis RA treatment. FN1 is an abundant ECM glycoprotein that orchestrates the assembly of other ECM components including collagen 
to provide a scaffold for cellular adhesion. Glycosylation of ECM proteins contributes to a dense stroma that is a hallmark of the tumor microenvironment in pancreatic cancer [36]. In order to determine whether enzymes mediating protein glycosylation are modulated by TGF $\beta$ and 9-cis RA treatment, we, therefore, performed gene expression analysis for an array of glycosylation enzymes. We found dysregulated expression of several genes including monoacylglycerol acyltransferase (MGAT) family and mannosyl oligosaccharide glucosidase (MOGS) and $\alpha$-glucosidase I upon TGF $\beta$ and 9-cis RA treated PANC-1 cells (Figure $4 \mathrm{~A}-\mathrm{C}$ ). We also observed increased expression of $\mathrm{O}$-linked $\mathrm{N}$-acetylglucosamine transferase (OGT) upon TGF $\beta$ and 9-cis RA treatment in PANC-1 cells, indicating their putative role in increased glycosylation (Figure 4D). Taken together, these findings suggest a possible role of RA signaling pathway in modulating increased fibrosis in PDAC (Figure 4E); this is a novel finding that warrants further investigations with a goal of developing improved therapeutic strategies that target desmoplasia in PDAC.

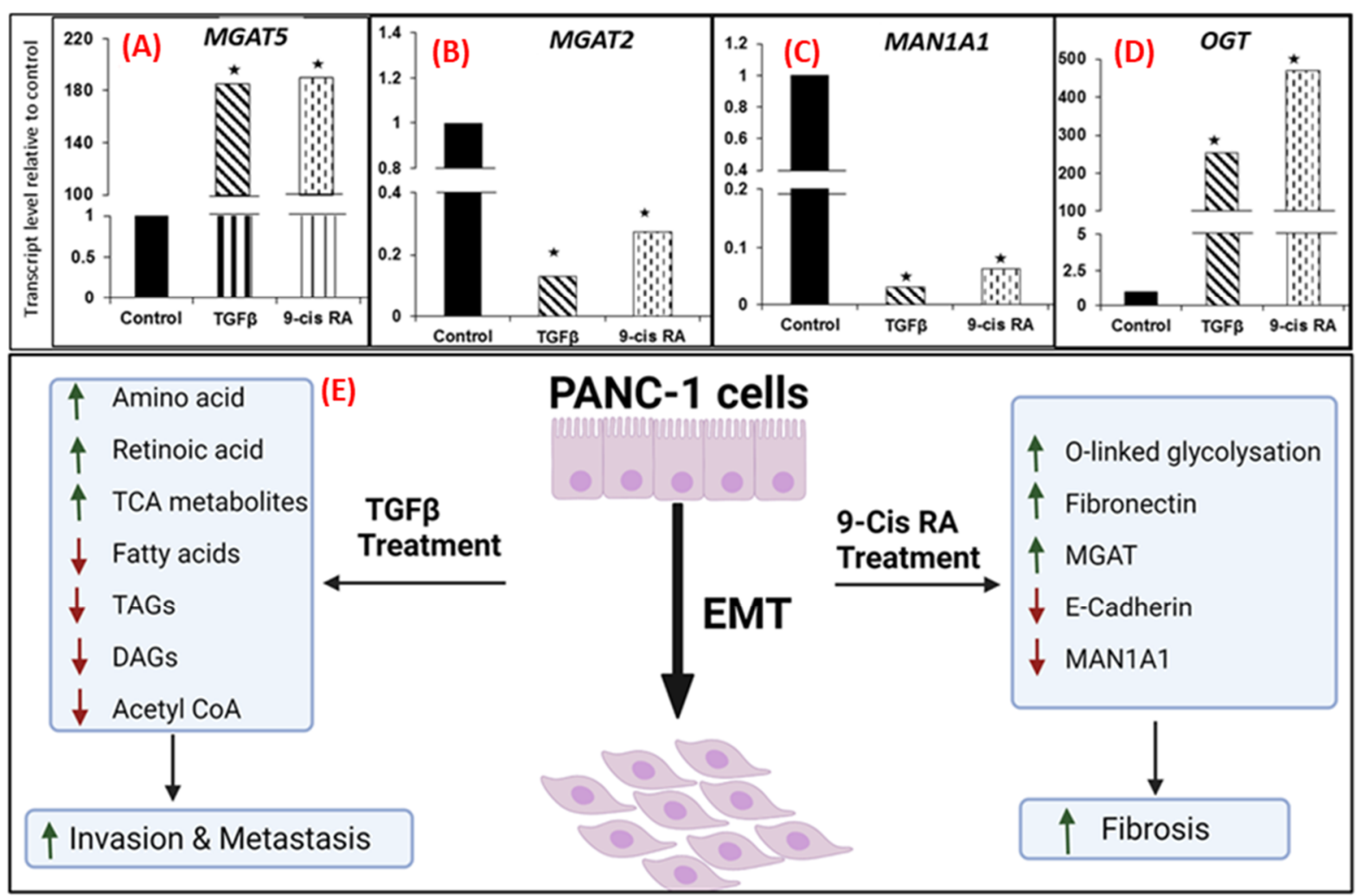

Figure 4. TGF $\beta$ and RA trigger metabolic dysreulations characteristic of an invasive metabotype. (A-D). TGF beta and 9-cis RA induce robust changes in the expression of genes involved in protein glycosylation. Relative expression of MGAT5, MGAT2, MAN1A1 and OGT in PANC-1 cells was performed using Taqman qRT-PCR method. Each bar shows transcript level of the mentioned genes in PANC-1 cells after treatments (TGF $\beta$ and 9-cis RA) relative to control after normalized to housekeeping genes. Data represent mean \pm SE from duplicate samples ( $p \leq 0.05)$. (E). Proposed model illustrating metabolic and gene expression alterations following TGF $\beta$ and 9-cis RA treatments in PANC-1 cells. TGF $\beta$ treatment caused an increase in intracellular retinoic acid levels and changes in amino acid, TCA metabolite and lipid profiles were also observed which may result in increased invasion and metastasis. 9-cis RA treatment alone decreased expression of E-cadherin with a concomitant increase in the levels of ECM protein such as FN1 resulting in likely contributions to increased fibrosis.

\subsection{Plasma Fibronectin, OGT and Acetyl CoA Levels Are Significantly Increased in Patients Diagnosed with Early Stage Pancreatic Cancer}

In order to ascertain clinical significance of the aforementioned findings, we used quantitative ELISA to determine the levels of fibronectin and OGT in plasma obtained from a well-defined cohort of early stage PDAC patients. Clinical and demographic 
characteristics of the cohort as age, sex and ethnicity are detailed in Table S7. Plasma levels of FN1 were significantly higher in PDAC patients $(572.85 \mu \mathrm{g} / \mathrm{mL})$ : a 23 -fold increase when compared to controls $(25.03 \mu \mathrm{g} / \mathrm{mL})$ (Figure 5A) and about 4-fold to 10-fold higher than compared to pancreatitis patients $(59.2 \mu \mathrm{g} / \mathrm{mL})$ and IPMN patients $(135.94 \mu \mathrm{g} / \mathrm{mL})$, respectively. Interestingly, plasma OGT levels (Figure 5B) were also significantly elevated in PDAC patients $(724.4 \mathrm{ng} / \mathrm{mL})$ compared to controls $(175.8 \mathrm{ng} / \mathrm{mL})$; however, there was no significant difference in mean values of OGT plasma concentrations between IPMN, pancreatitis and normal groups. We explored the relationship between FN1 and OGT levels and outcomes in the plasma of six PDAC patients in which clinical data were available. There was a modest correlation between FN1 level and time to progression; however, there was no correlation between FN1 and survival or OGT levels and outcome (Figure S6). The plasma upregulation of FN1 and OGT levels in PDAC patients can be potentially used as a prognostic marker of PDAC. Moreover, the plasma levels of acetyl CoA were found to be downregulated in clinical samples (Figure 5C), which may be corelated with our findings of an increase in TCA cycle metabolites and glycolytic flux in PANC-1 cells, towards a hypoxic tumor microenvironment.

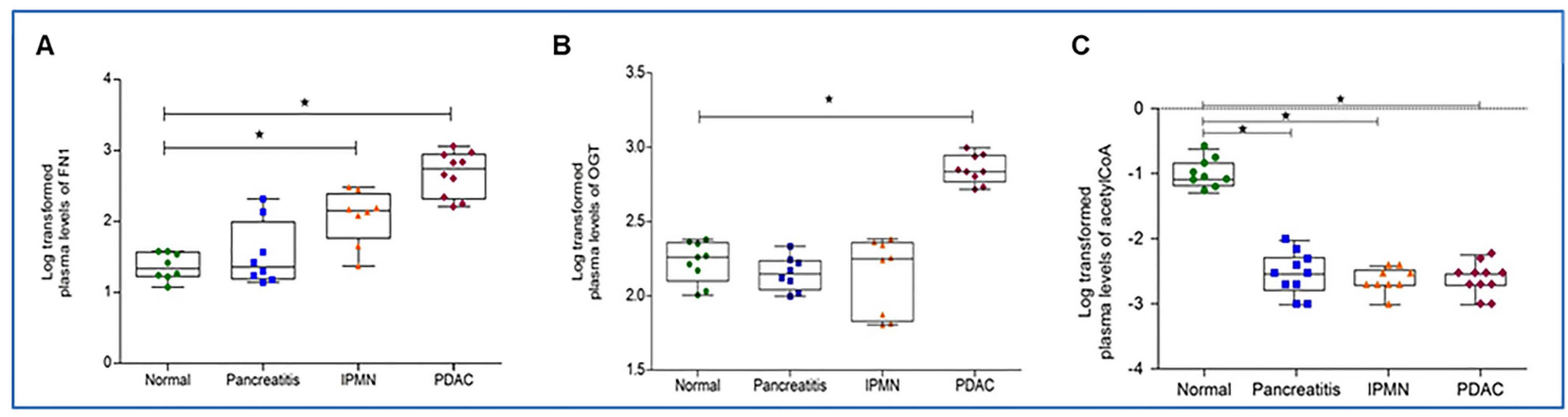

Figure 5. Increased levels of fibronectin, OGT and acetyl CoA in patient plasma samples correlate with pancreatic disease phenotype. FN1 (A) and OGT (B) levels in human plasma from patients with normal controls $(n=8)$, chronic pancreatitis $(n=8), \operatorname{IPMN}(n=8)$ as well as plasma from patients diagnosed with early stage PDAC $(n=10)$ as measured by ELISA. (C). Plasma levels of acetyl CoA in 11 PDAC, 9 IPMN, 10 pancreatitis and 9 normal samples as determined by UPLC-MRM MS. Target Lynx was used to obtain the response values for the metabolite in each sample, which was log transformed, and statistical analysis was carried out using GraphPad prism $\left.{ }^{*} p \leq 0.05\right)$.

\section{Discussion}

Epithelial-to-mesenchymal transition (EMT) has been extensively reported to contribute pathologically to fibrosis and cancer progression and reported as a key priming event for tumor development [37]. Pancreatic cancer is characterized by relatively smaller tumor volumes and a dense stroma that makes drug delivery a significant challenge [38]. While TGF $\beta$-mediated EMT in cancer cells is well documented, concomitant metabolic changes remain to be characterized [39]. Hence, the main focus of the study was to delineate metabolic dysregulations accompanying EMT induced by TGF $\beta$ treatment in PANC-1 cells. Here, for the first time, using a combinatorial metabolomics/lipidomics profiling approach, we discovered significant metabolic changes in PANC-1 cells upon TGF $\beta$ treatment that were subsequently validated by targeted quantitative mass spectrometry.

TGF $\beta$ treatment of PANC 1 cells resulted in significant perturbations in an array of biochemical pathways including energy, amino acid and lipid metabolism. For example, we observed a decrease in intracellular levels of acetyl-CoA and a concomitant upregulation in the levels of 2-hydroxyglutarate, fumarate, malate and isocitrate upon TGF $\beta$ treatment. This metabolic shift is likely to favour an increase in glycolytic flux conducive to a hypoxic tumor microenvironment. We also observed upregulation of several amino acids including branched chain amino acids (BCAA) (leucine, isoleucine and valine), glutamine and phenylalanine. Aberrant amino acid metabolism and aerobic glycolysis have been shown to play 
important roles in pancreatic cancer progression [40,41]. Glutamine is involved in multiple biological processes required for cancer cell growth and proliferation such as biosynthesis of glucosamine, purines, pyrimidines, non-essential amino acids and nicotinamide adenine dinucleotide (NAD). Notably, glutamine is an essential component of redox homeostasis and supports tumor growth of PDAC cells in an oncogenic KRAS-driven manner [42]. BCAAs serve as major nitrogen donors for alanine and glutamine synthesis and have an important role in protein synthesis [43]. Leucine, apart from being an important biological factor, also regulates the mammalian target of rapamycin (mTOR) pathway through nutrient signaling $[44,45]$. The mTOR pathway is recognized as a critical regulator of cellular function since it has roles in cell growth, proliferation and protein translation [46]. We also observed the upregulations of amino acid arginine and tryptophan that have recently been reported as effective targets of tumor immunotherapy as they have roles in the regulation of T-cell survival, proliferation and activation [47]. Finally, we observed significant dyslipidemia upon TGF $\beta$ treatment in PANC-1 cells that included downregulation of lipid species such as free fatty acids (FFAs) including myristoleic acid, oleic acid, linoleic acid, dihomo-linoleic acid, arachidonic acid and docosatetraenoic acid, LPEs, PSs and TAGs. Saturated and monounsaturated fatty acids have been shown to promote progression of pancreatic cancer [48]. In contrast, a metabolomics and transcriptomics study showed a decrease in the levels of lipase and a panel of fatty acids in pancreatic tumors [49]. Given the critical roles of metabolic crosstalk between cancer cells and stromal components, targeting metabolic vulnerabilities of TME may, thus, be considered a potentially effective therapeutic approach for PDAC treatment.

A novel finding of this study was the upregulation of 9-cis RA upon TGF $\beta$ treatment in pancreatic adenocarcinoma cells that harbor a mutant KRAS gene, while these changes were not apparent in Panc02.13 cells. Upregulation of retinoic acid, following TGF $\beta$ treatment, was confirmed in multiple pancreatic cancer cell lines using multiple reaction monitoring mass spectrometry. Although retinoic acid signaling is crucial for the developing pancreas and its interaction with other signaling cascades such as Wnt and TGF is well documented [50], the role of 9-cis RA signaling in TGF $\beta$ induced EMT is hitherto unreported. We found that treatment of PANC-1 and AsPC-1 cells with 9-cis RA induces the expression of major ECM proteins including fibronectin (FN1) and Collagen (COL3A). We further showed that 9-cis RA increased the migratory potential of these cells. It is reasonable to assume that increased FN1 levels could be driving EMT in these cells, contributing to the invasiveness in PDAC. Tumor cells have been reported to upregulate the expression of ECM proteins including FN1 to create a pro-tumor stromal environment [51]; however, further investigations are needed to delineate the precise role of 9-cis RA in mediating changes in the TME. Interestingly, the observed upregulation of amino acids and energy metabolism may contribute to a shift in to a more proliferative and invasive phenotype $[52,53]$. Future studies are needed to examine if upregulation of 9-cis RA is a generic phenomenon occurring in different cancer cell types undergoing TGF $\beta$-induced EMT. The upregulation of FN1 and COL3A was also confirmed in plasma samples obtained from patients with resectable PDAC. Interestingly, the plasma levels of these ECM proteins were found to increase progressively in patients carrying precursor lesions of pancreas (IPMN) and PDAC as compared to pancreatitis, thus emphasizing the potential utility of these proteins as prognostic markers for pancreatic carcinogenesis [33].

We also observed an upregulation of the enzyme O-GlcNAc transferase (OGT), which is in accordance with literature reports [54]. In order to further investigate glycosylation changes during EMT-related pancreatic cancer aggressiveness, we determined the gene expression of glycosylation enzymes after treatment with TGF $\beta$ and 9-cis RA. Using quantitative RT-PCR, we identified significant changes in the expression of MGAT5, MGAT2, MAN1A2, MOGS and OGT. MGAT gene codes for $\mathrm{N}$-acetyl glucosaminyl transferases that participates in N-glycosylation within the Golgi [55]. MGAT5 was significantly upregulated in both TGF $\beta$ and 9-cis RA treatments of PANC-1 cells. Interestingly, MGAT5 gene product GNTV is known to play a role in mediating aberrant elongation of branched N-glycans, re- 
sulting in the formation of complex tri-antennary and tetra-antennary structures associated with metastatic phenotype [56]. On the contrary, MGAT2, an enzyme involved in early branching, is significantly downregulated, and this agrees with reports that MGAT5 can transfer GlcNAc residues only in the absence of MGAT2. Taken together, we observed an alteration in the levels of MGAT that is consistent with increased branching of N-glycans. We also observed a decrease in MAN1A1 levels after both TGF $\beta$ and 9-cis RA treatments. MAN1A1 is a mannosidase enzyme that is responsible for the cleavage of mannose residues during biosynthesis of N-glycosylation of proteins making way for the addition of other sugar moieties, resulting in the formation of highly variable complex N-glycans. Our results concur with Legler et al., who have reported decreased MAN1A1 activity along with overexpression of MGAT5 in breast cancer cells that resulting in high cellular motility and invasiveness of these tumor cells [57]. Several studies have also explored the modulation of $\mathrm{N}$-glycans in leucocyte trafficking and how endothelial cells expressing N-glycans adhere to leucocytes $[58,59]$. It is possible that tumor cells could use similar mechanisms and adhere to vascular walls, thereby promoting extra vascularization.

In conclusion, these novel findings underscore the role of molecular phenotyping technologies for discovering previously unanticipated pathway perturbations with significant roles in promoting cancer metastasis and fibrosis. Our approach underscores the power of molecular phenotyping approaches that augment the identification of metabolic vulnerabilities of aggressive tumors that can potentially help in the development of novel therapeutics. Identification of molecular targets that can potentially alleviate stromal fibrosis is likely to improve local drug delivery relative to the proliferating tumor, thus impacting the success of therapeutic regimens and clinical outcomes in pancreatic cancer.

Supplementary Materials: The following are available online at https: / www.mdpi.com/article/ 10.3390 / cancers13246204/s1, Table S1. Statistical analysis of untargeted profiling data comparing PANC-1 cells treated with either TGF $\beta$ or DMSO; Table S2. Full list of tandem MS validated metabolites with details; Table S3. Statistical analysis results for the amino acid quantitation by targeted MRM-MS using UPLC-TQS comparing PANC-1 cells treated either with TGF $\beta$ or DMSO; Table S4. List of significantly dysregulated targeted MRM-MS data using QTRAP 7500 comparing PANC-1 cells treated either with TGF $\beta$ or DMSO; Table S5. Q1/Q3 transitions for metabolites quantified using multiple reaction monitoring mass spectrometry (MRM-MS); Table S6. The CT values for EMT-array gene expresion in PANC-1 cells after treatment with 9-cis-RA and TGF $\beta$ treatment; Table S7.Demographic details of the study participants; Figure S1. MRM MS analysis of acetyl CoA in human plasma. Panel (A). Representative chromatogram for acetyl CoA and the internal standard adenosine-2-D1. Panel (B). LC gradient used for acetyl CoA detection. Panels (C) and (D). A six point standard calibration curve for acetyl CoA; Figure S2. TGF $\beta$ treatment induced morphological changes in PANC-1 cells along with significant changes in the EMT markers (Panels A-D). Panel (A). Phase contrast images of PANC-1 cells treated with $10 \mathrm{ng} / \mathrm{mL}$ of TGF $\beta$ (right) and control cells (left). Panel (B). Bar graph showing significant down regulation in E- cadherin and concominant upregulation in N-cadherin. Panels (C) and D. Western blot analysis of altered levels of E-cadherin and N-cadherin in PANC-1 cells treated with $10 \mathrm{ng} / \mathrm{mL}$ of TGF $\beta$ (T) compared to control cells (C). TGF $\beta$ treatment did not induce EMT associated changes in Panc02.13 cells (Panels $(\mathrm{E}-\mathrm{H})$ ). Panel $€$. Phase contrast images of Panc02.13 cells treated with $10 \mathrm{ng} / \mathrm{mL}$ of TGF $\beta$ (right) and control cells (left). Panel (F). Bar graph showing statistically insignificant decrease in E-cadherin levels in Panc02.13 cells after TGF $\beta$ treatment. Panels $(G, H)$. Western blot analysis of E-cadherin and $\mathrm{N}$-cadherin in Panc02.13 cells treated with10 ng/mL of TGF $\beta$ (right) and control cells (left). Panel (I). Determination of endogenous levels of 9-cis-RA in PANC-1 and Panc02.13 by UPLC-MRM-MS. Panel (J). MS/MS validations of a subset of metabolites that were found to be significantly dysregulated in PANC-1 cells upon TGF $\beta$ treatment. Phase contrast (Panel $(\mathrm{K})$ ) and western blot (Panels $(\mathrm{L}, \mathrm{M})$ showing no change in morphology and EMT marker proteins upon (at) RA treatment; Figure S3. UPLC-MRM MS analysis of 9-cis retinoic acid in PANC-1 cells upon treatment with TGF $\beta$. Panel (A). A representative chromatogram showing 9-cis RA peak. Panel (B,C). Description of LC-method used for resolution and detection of 9-cis RA. Panel (D). A six point standard calibration curve for 9-cis RA; Figure S4. Altered intracellular levels of collagen upon TGF $\beta$ and 9-cis RA treatment in PANC-1 cells. Western blot analysis of collagen protein levels in PANC-1 cells for the same set of treatments. 
Quantitative analysis was performed using BioRad Quantity One software. GAPDH was used for normalization. All $p$ values were calculated using Student's t test. ${ }^{*}, p \leq 0.05$; Figure S5. In Vitro scratch assay showing the effect of TGF $\beta$ and 9-Cis RA treatment on PANC-1 and AsPC-1 cells. Cell migration images of scratch assay at 0,24 and $48 \mathrm{~h}$ and bar graph presenting the wound area closure $\%$ based on scratch assay experiment for PANC-1 (Panel A) and AsPC-1 cells (Panel B); Figure S6. Correlation analysis suggesting moderate correlation between FN1 levels (as estimated by ELISA) and time of progression of PDAC. Patients with late progression tend to show lower plasma FN1 levels; Supplementary methods: RNA extraction and cDNA transcription; Real Time-Polymerase Chain Reaction (RT-PCR) on EMT related genes; Western blot analysis; 4 Scratch Assay; 9-cis RA MRM analysis in PANC-1 cells; MRM-MS analysis of amino acids; Validation of metabolites by targeted analysis in plasma samples; Figure S7. Primary Data for Supplementary Figure S2, panel C. References $[21,60]$ are cited in the supplementary materials.

Author Contributions: Conceptualization, M.U.R., S.B. (Shivani Bansal), A.K.C.; methodology, M.U.R., S.B. (Shivani Bansal), P.K., S.K.J., T.A., C.P.H., Y.L., J.M., B.S., S.B. (Sunil Bansal), S.K.C., R.S., P.P.B., M.M., M.S.F., H.J.F., K.U., J.P.S. and A.K.C.; software, M.U.R., S.B. (Shivani Bansal), Y.L.; validation, M.U.R., S.B. (Shivani Bansal), P.K., T.A., C.P.H., Y.L. and A.K.C.; formal analysis, M.U.R., S.B. (Shivani Bansal), P.K., S.K.J., T.A., C.P.H., Y.L., J.M., B.S., S.B. (Sunil Bansal), S.K.C., R.S., P.P.B., M.M., M.S.F., H.J.F., K.U., J.P.S. and A.K.C.; investigation, M.U.R., S.B. (Shivani Bansal), P.K., S.K.J., T.A., C.P.H., Y.L., J.M., B.S., S.B. (Sunil Bansal), S.K.C., R.S., P.P.B., M.M., M.S.F., H.J.F., K.U., J.P.S. and A.K.C.; resources, A.K.C.; data curation, M.U.R., S.B. (Shivani Bansal), P.K., S.K.J., T.A., C.P.H., Y.L., J.M., B.S., S.B. (Sunil Bansal), S.K.C., R.S., P.P.B., M.M., M.S.F., H.J.F., K.U and, J.P.S.; writing—original draft preparation, M.U.R., S.B. (Shivani Bansal) and A.K.C.; writing-review and editing, M.U.R., S.B. (Shivani Bansal), P.K., S.K.J., T.A., C.P.H., Y.L., J.M., B.S., S.B. (Sunil Bansal), S.K.C., R.S., P.P.B., M.M., M.S.F., H.J.F., K.U., J.P.S. and A.K.C.; visualization, M.U.R., S.B. (Shivani Bansal), Y.L. and A.K.C.; supervision, A.K.C.; project administration, A.K.C.; funding acquisition, A.K.C. All authors have read and agreed to the published version of the manuscript.

Funding: This study was supported by American Cancer Society (IRG-92-152-17 award number AWD4470404), Georgetown Lombardi Comprehensive Cancer Center Support Grant Developmental Funds and Ruesch Foundation to K.U. and A.K.C.

Institutional Review Board Statement: The samples were collected on a study that was conducted according to the guidelines of the Declaration of Helsinki, and approved by the Institutional Review Board of The University of Rochester (RSRB \#15852) which was approved on 14 October 2012 and by the Institutional Review Board (or Ethics Committee) of Georgetown University (protocol code 2013-0049 and initial approval of 23 January 2013).

Informed Consent Statement: Informed consent was obtained from all participants involved in the study.

Data Availability Statement: Not applicable.

Acknowledgments: We would like to thank the microscopy shared resource, the genomics and epigenomics shared resource and the metabolomics shared resource in Georgetown University (Washington, DC, USA) partly supported by NIH/NCI/CCSG grant P30-CA051008.

Conflicts of Interest: The authors declare no conflict of interest.

\section{References}

1. Rahib, L.; Smith, B.D.; Aizenberg, R.; Rosenzweig, A.B.; Fleshman, J.M.; Matrisian, L.M. Projecting cancer incidence and deaths to 2030: The unexpected burden of thyroid, liver, and pancreas cancers in the United States. Cancer Res. 2014, 74, 2913-2921. [CrossRef] [PubMed]

2. Vincent, A.; Herman, J.; Schulick, R.; Hruban, R.H.; Goggins, M. Pancreatic cancer. Lancet 2011, 378, 607-620. [CrossRef]

3. Rawla, P.; Sunkara, T.; Gaduputi, V. Epidemiology of Pancreatic Cancer: Global Trends, Etiology and Risk Factors. World J. Oncol. 2019, 10, 10-27. [CrossRef]

4. Singh, A.; Settleman, J. EMT, cancer stem cells and drug resistance: An emerging axis of evil in the war on cancer. Oncogene 2010, 29, 4741-4751. [CrossRef]

5. $\quad$ Sheen, Y.Y.; Kim, M.J.; Park, S.A.; Park, S.Y.; Nam, J.S. Targeting the Transforming Growth Factor-beta Signaling in Cancer Therapy. Biomol. Ther. 2013, 21, 323-331. [CrossRef] 
6. Rhim, A.D.; Mirek, E.T.; Aiello, N.M.; Maitra, A.; Bailey, J.M.; McAllister, F.; Reichert, M.; Beatty, G.L.; Rustgi, A.K.; Vonderheide, R.H.; et al. EMT and dissemination precede pancreatic tumor formation. Cell 2012, 148, 349-361. [CrossRef]

7. Hotz, B.; Arndt, M.; Dullat, S.; Bhargava, S.; Buhr, H.J.; Hotz, H.G. Epithelial to mesenchymal transition: Expression of the regulators snail, slug, and twist in pancreatic cancer. Clin. Cancer Res. 2007, 13, 4769-4776. [CrossRef]

8. Craven, K.E.; Gore, J.; Korc, M. Overview of pre-clinical and clinical studies targeting angiogenesis in pancreatic ductal adenocarcinoma. Cancer Lett. 2016, 381, 201-210. [CrossRef] [PubMed]

9. Neuzillet, C.; Tijeras-Raballand, A.; Cohen, R.; Cros, J.; Faivre, S.; Raymond, E.; de Gramont, A. Targeting the TGFbeta pathway for cancer therapy. Pharmacol. Ther. 2015, 147, 22-31. [CrossRef]

10. Hezel, A.F.; Deshpande, V.; Zimmerman, S.M.; Contino, G.; Alagesan, B.; O'Dell, M.R.; Rivera, L.B.; Harper, J.; Lonning, S.; Brekken, R.A.; et al. TGF-beta and alphavbeta6 integrin act in a common pathway to suppress pancreatic cancer progression. Cancer Res. 2012, 72, 4840-4845. [CrossRef] [PubMed]

11. Aoyagi, Y.; Oda, T.; Kinoshita, T.; Nakahashi, C.; Hasebe, T.; Ohkohchi, N.; Ochiai, A. Overexpression of TGF-beta by infiltrated granulocytes correlates with the expression of collagen mRNA in pancreatic cancer. Br. J. Cancer 2004, 91, 1316-1326. [CrossRef] [PubMed]

12. Hidalgo, M.; Von Hoff, D.D. Translational therapeutic opportunities in ductal adenocarcinoma of the pancreas. Clin. Cancer Res. 2012, 18, 4249-4256. [CrossRef] [PubMed]

13. Olive, K.P.; Jacobetz, M.A.; Davidson, C.J.; Gopinathan, A.; McIntyre, D.; Honess, D.; Madhu, B.; Goldgraben, M.A.; Caldwell, M.E.; Allard, D.; et al. Inhibition of Hedgehog signaling enhances delivery of chemotherapy in a mouse model of pancreatic cancer. Science 2009, 324, 1457-1461. [CrossRef] [PubMed]

14. Heldin, C.H.; Rubin, K.; Pietras, K.; Ostman, A. High interstitial fluid pressure-An obstacle in cancer therapy. Nat. Rev. Cancer 2004, 4, 806-813. [CrossRef] [PubMed]

15. Jung, H.Y.; Fattet, L.; Yang, J. Molecular pathways: Linking tumor microenvironment to epithelial-mesenchymal transition in metastasis. Clin. Cancer Res. 2015, 21, 962-968. [CrossRef] [PubMed]

16. Jaffee, E.M.; Schutte, M.; Gossett, J.; Morsberger, L.A.; Adler, A.J.; Thomas, M.; Greten, T.F.; Hruban, R.H.; Yeo, C.J.; Griffin, C.A. Development and characterization of a cytokine-secreting pancreatic adenocarcinoma vaccine from primary tumors for use in clinical trials. Cancer J. Sci. Am. 1998, 4, 194-203.

17. Olson, B.J.; Markwell, J. Assays for determination of protein concentration. Curr. Protoc. Pharmacol. 2007, 73, A-3A. [CrossRef]

18. Gowda, H.; Ivanisevic, J.; Johnson, C.H.; Kurczy, M.E.; Benton, H.P.; Rinehart, D.; Nguyen, T.; Ray, J.; Kuehl, J.; Arevalo, B.; et al. Interactive XCMS Online: Simplifying advanced metabolomic data processing and subsequent statistical analyses. Anal. Chem. 2014, 86, 6931-6939. [CrossRef] [PubMed]

19. Xia, J.; Psychogios, N.; Young, N.; Wishart, D.S. MetaboAnalyst: A web server for metabolomic data analysis and interpretation. Nucleic Acids Res. 2009, 37, W652-W660. [CrossRef] [PubMed]

20. Dunn, W.B.; Broadhurst, D.; Begley, P.; Zelena, E.; Francis-McIntyre, S.; Anderson, N.; Brown, M.; Knowles, J.D.; Halsall, A.; Haselden, J.N.; et al. Procedures for large-scale metabolic profiling of serum and plasma using gas chromatography and liquid chromatography coupled to mass spectrometry. Nat. Protoc. 2011, 6, 1060-1083. [CrossRef]

21. Kane, M.A.; Napoli, J.L. Quantification of endogenous retinoids. Methods Mol. Biol. 2010, 652, 1-54. [CrossRef] [PubMed]

22. Mapstone, M.; Cheema, A.K.; Fiandaca, M.S.; Zhong, X.; Mhyre, T.R.; MacArthur, L.H.; Hall, W.J.; Fisher, S.G.; Peterson, D.R.; Haley, J.M.; et al. Plasma phospholipids identify antecedent memory impairment in older adults. Nat. Med. 2014, 20, 415-418. [CrossRef] [PubMed]

23. Nakajima, S.; Doi, R.; Toyoda, E.; Tsuji, S.; Wada, M.; Koizumi, M.; Tulachan, S.S.; Ito, D.; Kami, K.; Mori, T.; et al. N-cadherin expression and epithelial-mesenchymal transition in pancreatic carcinoma. Clin. Cancer Res. 2004, 10, 4125-4133. [CrossRef] [PubMed]

24. Matters, G.L.; McGovern, C.; Harms, J.F.; Markovic, K.; Anson, K.; Jayakumar, C.; Martenis, M.; Awad, C.; Smith, J.P. Role of endogenous cholecystokinin on growth of human pancreatic cancer. Int. J. Oncol. 2011, 38, 593-601. [CrossRef] [PubMed]

25. Matters, G.L.; Cooper, T.K.; McGovern, C.O.; Gilius, E.L.; Liao, J.; Barth, B.M.; Kester, M.; Smith, J.P. Cholecystokinin mediates progression and metastasis of pancreatic cancer associated with dietary fat. Dig. Dis. Sci. 2014, 59, 1180-1191. [CrossRef]

26. Malchiodi, Z.X.; Cao, H.; Gay, M.D.; Safronenka, A.; Bansal, S.; Tucker, R.D.; Weinberg, B.A.; Cheema, A.; Shivapurkar, N.; Smith, J.P. Cholecystokinin Receptor Antagonist Improves Efficacy of Chemotherapy in Murine Models of Pancreatic Cancer by Altering the Tumor Microenvironment. Cancers 2021, 13, 4949. [CrossRef]

27. Lei, S.; Dubeykovskiy, A.; Chakladar, A.; Wojtukiewicz, L.; Wang, T.C. The murine gastrin promoter is synergistically activated by transforming growth factor-beta/Smad and Wnt signaling pathways. J. Biol. Chem. 2004, 279, 42492-42502. [CrossRef]

28. Morandi, A.; Taddei, M.L.; Chiarugi, P.; Giannoni, E. Targeting the Metabolic Reprogramming That Controls Epithelial-toMesenchymal Transition in Aggressive Tumors. Front. Oncol. 2017, 7, 40. [CrossRef]

29. Mayers, J.R.; Wu, C.; Clish, C.B.; Kraft, P.; Torrence, M.E.; Fiske, B.P.; Yuan, C.; Bao, Y.; Townsend, M.K.; Tworoger, S.S.; et al. Elevation of circulating branched-chain amino acids is an early event in human pancreatic adenocarcinoma development. Nat. Med. 2014, 20, 1193-1198. [CrossRef]

30. Shah, S.; Pishvaian, M.J.; Easwaran, V.; Brown, P.H.; Byers, S.W. The role of cadherin, beta-catenin, and AP-1 in retinoid-regulated carcinoma cell differentiation and proliferation. J. Biol. Chem. 2002, 277, 25313-25322. [CrossRef] 
31. Byers, S.; Pishvaian, M.; Crockett, C.; Peer, C.; Tozeren, A.; Sporn, M.; Anzano, M.; Lechleider, R. Retinoids increase cell-cell adhesion strength, beta-catenin protein stability, and localization to the cell membrane in a breast cancer cell line: A role for serine kinase activity. Endocrinology 1996, 137, 3265-3273. [CrossRef] [PubMed]

32. Weissmueller, S.; Manchado, E.; Saborowski, M.; Morris, J.P.; Wagenblast, E.; Davis, C.A.; Moon, S.H.; Pfister, N.T.; Tschaharganeh, D.F.; Kitzing, T.; et al. Mutant p53 drives pancreatic cancer metastasis through cell-autonomous PDGF receptor beta signaling. Cell 2014, 157, 382-394. [CrossRef] [PubMed]

33. Peng, C.; Zhu, Y.; Zhang, W.; Liao, Q.; Chen, Y.; Zhao, X.; Guo, Q.; Shen, P.; Zhen, B.; Qian, X.; et al. Regulation of the Hippo-YAP Pathway by Glucose Sensor O-GlcNAcylation. Mol. Cell 2017, 68, 591-604.e595. [CrossRef] [PubMed]

34. Liang, D.; Wang, Y.; Zhu, Z.; Yang, G.; An, G.; Li, X.; Niu, P.; Chen, L.; Tian, L. BMP-7 attenuated silica-induced pulmonary fibrosis through modulation of the balance between TGF-beta/Smad and BMP-7/Smad signaling pathway. Chem. Biol. Interact. 2016, 243, 72-81. [CrossRef] [PubMed]

35. Pohlers, D.; Brenmoehl, J.; Loffler, I.; Muller, C.K.; Leipner, C.; Schultze-Mosgau, S.; Stallmach, A.; Kinne, R.W.; Wolf, G. TGF-beta and fibrosis in different organs-Molecular pathway imprints. Biochim. Biophys. Acta 2009, 1792, 746-756. [CrossRef] [PubMed]

36. Pannkuk, E.L.; Laiakis, E.C.; Mak, T.D.; Astarita, G.; Authier, S.; Wong, K.; Fornace, A.J., Jr. A Lipidomic and Metabolomic Serum Signature from Nonhuman Primates Exposed to Ionizing Radiation. Metabolomics 2016, 12, 80. [CrossRef] [PubMed]

37. Dudas, J.; Ladanyi, A.; Ingruber, J.; Steinbichler, T.B.; Riechelmann, H. Epithelial to Mesenchymal Transition: A Mechanism that Fuels Cancer Radio/Chemoresistance. Cells 2020, 9, 428. [CrossRef]

38. Erkan, M.; Hausmann, S.; Michalski, C.W.; Fingerle, A.A.; Dobritz, M.; Kleeff, J.; Friess, H. The role of stroma in pancreatic cancer: Diagnostic and therapeutic implications. Nat. Rev. Gastroenterol. Hepatol. 2012, 9, 454-467. [CrossRef]

39. Massague, J.; Blain, S.W.; Lo, R.S. TGFbeta signaling in growth control, cancer, and heritable disorders. Cell 2000, 103, 295-309. [CrossRef]

40. Yang, J.; Ren, B.; Yang, G.; Wang, H.; Chen, G.; You, L.; Zhang, T.; Zhao, Y. The enhancement of glycolysis regulates pancreatic cancer metastasis. Cell. Mol. Life Sci. 2020, 77, 305-321. [CrossRef]

41. Li, J.; Gu, D.; Lee, S.S.; Song, B.; Bandyopadhyay, S.; Chen, S.; Konieczny, S.F.; Ratliff, T.L.; Liu, X.; Xie, J.; et al. Abrogating cholesterol esterification suppresses growth and metastasis of pancreatic cancer. Oncogene 2016, 35, 6378-6388. [CrossRef] [PubMed]

42. Son, J.; Lyssiotis, C.A.; Ying, H.; Wang, X.; Hua, S.; Ligorio, M.; Perera, R.M.; Ferrone, C.R.; Mullarky, E.; Shyh-Chang, N.; et al. Glutamine supports pancreatic cancer growth through a KRAS-regulated metabolic pathway. Nature 2013, 496, 101-105. [CrossRef] [PubMed]

43. Garber, A.J.; Karl, I.E.; Kipnis, D.M. Alanine and glutamine synthesis and release from skeletal muscle. II. The precursor role of amino acids in alanine and glutamine synthesis. J. Biol. Chem. 1976, 251, 836-843. [CrossRef]

44. Nicklin, P.; Bergman, P.; Zhang, B.; Triantafellow, E.; Wang, H.; Nyfeler, B.; Yang, H.; Hild, M.; Kung, C.; Wilson, C.; et al. Bidirectional transport of amino acids regulates mTOR and autophagy. Cell 2009, 136, 521-534. [CrossRef] [PubMed]

45. Avruch, J.; Long, X.; Ortiz-Vega, S.; Rapley, J.; Papageorgiou, A.; Dai, N. Amino acid regulation of TOR complex 1. Am. J. Physiol. Endocrinol. Metab. 2009, 296, E592-E602. [CrossRef]

46. Laplante, M.; Sabatini, D.M. mTOR signaling at a glance. J. Cell Sci. 2009, 122, 3589-3594. [CrossRef]

47. Wei, Z.; Liu, X.; Cheng, C.; Yu, W.; Yi, P. Metabolism of Amino Acids in Cancer. Front. Cell Dev. Biol. 2020, 8, 603837. [CrossRef]

48. Straub, B.K.; Herpel, E.; Singer, S.; Zimbelmann, R.; Breuhahn, K.; Macher-Goeppinger, S.; Warth, A.; Lehmann-Koch, J.; Longerich, T.; Heid, H.; et al. Lipid droplet-associated PAT-proteins show frequent and differential expression in neoplastic steatogenesis. Mod. Pathol. 2010, 23, 480-492. [CrossRef] [PubMed]

49. Grippo, P.J.; Fitchev, P.S.; Bentrem, D.J.; Melstrom, L.G.; Dangi-Garimella, S.; Krantz, S.B.; Heiferman, M.J.; Chung, C.; Adrian, K.; Cornwell, M.L.; et al. Concurrent PEDF deficiency and Kras mutation induce invasive pancreatic cancer and adipose-rich stroma in mice. Gut 2012, 61, 1454-1464. [CrossRef]

50. Hu, X.; Gao, J.; Liao, Y.; Tang, S.; Lu, F. Retinoic acid alters the proliferation and survival of the epithelium and mesenchyme and suppresses Wnt/beta-catenin signaling in developing cleft palate. Cell Death Dis. 2013, 4, e898. [CrossRef]

51. Efthymiou, G.; Saint, A.; Ruff, M.; Rekad, Z.; Ciais, D.; Van Obberghen-Schilling, E. Shaping Up the Tumor Microenvironment With Cellular Fibronectin. Front. Oncol. 2020, 10, 641. [CrossRef]

52. Wang, J.; Wang, B.; Ren, H.; Chen, W. miR-9-5p inhibits pancreatic cancer cell proliferation, invasion and glutamine metabolism by targeting GOT1. Biochem. Biophys. Res. Commun. 2019, 509, 241-248. [CrossRef]

53. Xu, R.; Yang, J.; Ren, B.; Wang, H.; Yang, G.; Chen, Y.; You, L.; Zhao, Y. Reprogramming of Amino Acid Metabolism in Pancreatic Cancer: Recent Advances and Therapeutic Strategies. Front. Oncol. 2020, 10, 572722. [CrossRef] [PubMed]

54. Ma, Z.; Vocadlo, D.J.; Vosseller, K. Hyper-O-GlcNAcylation is anti-apoptotic and maintains constitutive NF-kappaB activity in pancreatic cancer cells. J. Biol. Chem. 2013, 288, 15121-15130. [CrossRef] [PubMed]

55. Pinho, S.S.; Reis, C.A. Glycosylation in cancer: Mechanisms and clinical implications. Nat. Rev. Cancer 2015, 15, 540-555. [CrossRef]

56. Oliveira-Ferrer, L.; Legler, K.; Milde-Langosch, K. Role of protein glycosylation in cancer metastasis. Semin. Cancer Biol. 2017, 44, 141-152. [CrossRef] [PubMed] 
57. Legler, K.; Rosprim, R.; Karius, T.; Eylmann, K.; Rossberg, M.; Wirtz, R.M.; Muller, V.; Witzel, I.; Schmalfeldt, B.; Milde-Langosch, K.; et al. Reduced mannosidase MAN1A1 expression leads to aberrant N-glycosylation and impaired survival in breast cancer. Br. J. Cancer 2018, 118, 847-856. [CrossRef]

58. Sperandio, M.; Gleissner, C.A.; Ley, K. Glycosylation in immune cell trafficking. Immunol. Rev. 2009, 230, 97-113. [CrossRef] [PubMed]

59. Chacko, B.K.; Scott, D.W.; Chandler, R.T.; Patel, R.P. Endothelial surface N-glycans mediate monocyte adhesion and are targets for anti-inflammatory effects of peroxisome proliferator-activated receptor gamma ligands. J. Biol. Chem. 2011, 286, 38738-38747. [CrossRef]

60. Suarez-Arnedo, A.; Figueroa, F.T.; Clavijo, C.; Arbeláez, P.; Cruz, J.C.; Muñoz-Camargo, C. An image J plugin for the high throughput image analysis of in vitro scratch wound healing assays. PLoS ONE, 2020, 15, e0232565. 